\title{
Pengaruh Motivasi Belajar, Kemampuan Pemecahan Masalah, dan Hasil Belajar Terhadap Kesiapan Kerja Siswa Kelas XII Pemesinan SMK Pemuda 3 Kesamben, Blitar
}

\author{
Rifqi Aziz ${ }^{1}$, Basuki ${ }^{2}$, dan Agus Suyetno ${ }^{3}$ \\ 1,2,3 Jurusan Teknik Mesin Fakultas Teknik Universitas Negeri Malang \\ e-mail: rifki19aziz@gmail.com
}

\begin{abstract}
Abstrak: Pendidikan merupakan upaya peningkatan mutu siswa untuk mengikuti perkembangan teknologi serta menambah wawasan yang luas agar mampu bersaing di pendidikan selanjutnya atau dalam dunia kerja. Dalam upaya peningkatan mutu siswa di pengaruhi oleh motivasi belajar, kemampuan pemecahan masalah, dan hasil belajar. Penelitian ini bertujuan untuk mengetahui: (1) Pengaruh Motivasi Belajar terhadap Kesiapan Kerja Siswa (2) Pengaruh Kemampuan Pemecahan Masalah terhadap Kesiapan Kerja Siswa (3) Pengaruh Hasil Belajar terhadap Kesiapan Kerja (4) Pengaruh Motivasi Belajar, Kemampuan Pemecahan Masalah, dan Hasil Belajar Terhadap Kesiapan Kerja. Penelitian ini merupakan penelitian ex post-facto. Subyek penelitian ini adalah seluruh siswa kelas XII Pemesinan SMK Pemuda 3 Kesamben, Blitar sebanyak 94 siswa. Pengumpulan data menggunakan metode angket dan dokumentasi. Uji coba instrumen penelitian dilaksanakan di SMK Pemuda 3 Kesamben, Blitar. Pengujian analisis meliputi uji linearitas dan uji multikolinearitas. Teknik analisis data yang digunakan adalah teknik analisis regresi sederhana untuk hepotesis pertama, hipotesis kedua, hipotesis ketiga serta analisis regresi ganda untuk hipotesis keempat. Berdasarkan hasil penelitian pada hipotesis pertama sebesar 75,7\% yang berarti berpengaruh langsung; hipotesis kedua sebesar $83,3 \%$ yang berpengaruh langsung; hipotesis ketiga sebesar 2,6\% yang berarti berpengaruh tidak langsung; sedangkan hipotesis keempat sebesar 23,3\% untuk motivasi belajar, $65,7 \%$ untuk kemampuan pemecahan masalah, dan $2,7 \%$ untuk hasil belajar yang berarti terdapat pengaruh langsung dan tidak langsung terhadap kesiapan kerja siswa kelas XII Pemesinan SMK Pemuda 3 Kesamben, Blitar.
\end{abstract}

Kata Kunci: Motivasi Belajar, Kemampuan Pemecahan Masalah, Hasil Belajar, Dan Kesiapan Kerja.

\begin{abstract}
Education is the quality improvement efforts of students to follow technological developments as well as add a breadth in order to be able to compete in further education or in the world of work. In an attempt to influence students in quality improvement by the motivation to learn, problem-solving ability, and the results of the study. This research aims to know the: (1) influence of Learning Motivation towards Work Readiness of students (2) Influences the ability of problem solving students ' Work against Italy (3) Influence the Learning Outcome against Italy work (4) influence of Learning Motivation, Ability of problem solving, and Learning Outcomes against the Work Readiness. This research is the research of ex post-facto. The subject of this research is the whole grade Machining XII SMK Pemuda 3 Kesamben, Blitar as much as 94 students. Now using the method of data collection and documentation. Test instrument of research carried out in the SMK Pemuda 3 Kesamben, Blitar. Testing analysis of the linearity test and the test covers multicollinearity. Data analysis technique used is a simple regression analysis techniques to hepotesis first, second third hypothesis, hypothesis and regression analysis of the double for the fourth hypothesis. Based on the results of research on the first hypothesis of $75.7 \%$ which means the direct effect; the second hypothesis of $83.3 \%$ of the direct effect; the third hypothesis of $2.6 \%$ which means the effect is not immediate; whereas the fourth hypothesis of $23.3 \%$ to $65.7 \%$, learning motivation for problem-solving ability, and $2.7 \%$ for the results of a study which means there is a direct and indirect influence against the working class XII student readiness Machining SMK Pemuda 3 Kesamben, Blitar.
\end{abstract}

Keywords: The Motivation To Learn, Problem-Solving Abilities, Learning Outcomes, And Work Readiness 
Perkembangan teknologi di Indonesia semakin pesat dari waktu ke waktu mewajibkan siswa untuk dapat mengikuti arus perkembangan teknologi dengan meningkatkan mutu pendidikan yang ditempuh selama masa sekolah. Pendidikan merupakan salah satu pondasi untuk membuat sumber daya manusia (SDM) yang handal dan berwawasan luas agar mampu bersaing di pendidikan selanjutnya atau dalam dunia kerja. Pendidikan merupakan upaya membina manusia dengan segenap potensi yang dimiliki agar seimbang sehingga dapat melahirkan manusia seutuhnya. Pendidikan tidak hanya menekankan segi pengetahuan saja, tetapi juga harus menekankan sisi emosi, rohani, hidup bersama dan lain-lain. Pendidikan yang hanya memprioritaskan sisi pengetahuan akan menyebabkan peserta didik tidak dapat berkembang menjadi manusia yang lebih baik.

Dalam dunia pendidikan di indonesia yang terjadi sekarang banyak sekolah yang mementingkan sisi pendidikannya namun tidak memperhatikan karakter siswa. Seperti halnya negara indonesia merupakan negara tingkat pengangguran yang cukup tinggi, itu dipengaruhi karena karakter siswa yang belum sesuai dengan dunia kerja. Oleh sebab itu motivasi belajar, kemampuan pemecahan masalah, dan hasil belajar harus ditingkatkan terutama bagi siswa kelas XII. Dalam penelitian ini sampel yang di ambil siswa kelas XII jurusan teknik mesin.

Menurut Khodijah (2014:150-151), menjelaskan bahwa motivasi belajar sebagai suatu dorongan yang mengubah energi dalam diri seseorang kedalam bentuk aktivitas nyata untuk mencapai tujuan tertentu. Dengan kata lain motivasi adalah psikologis yang mendorong seseorang untuk melakukan sesuatu. Sedangkan motivasi belajar adalah kondisi psikologi yang mendorong seseorang untuk belajar.

Haling (2007:5) mengemukakan bahwa motivasi belajar adalah perilaku belajar yang dilakukan oleh seorang pelajar. Sedangkan Djamarah (2002) berpendapat bahwa motivasi belajar merupakan aktor utama yang menetukan keberhasilan belajarnya. Berdasarkan pendapat diatas, dapat diambil kesimpulan bahwa motivasi belajar adalah dorongan atau rangsangan dari dalam diri seseorang yang dapat meningkatkan kemauan dan melakukan kegiatan atau aktivitas belajar agar tujuan belajar tercapai.

Menurut Sumarmo (1994) mengartikan pemecahan masalah sebagai kegiatan menyelesaikan soal, menyelesaikan soal yang tidak rutin, mengaplikasikan matematika dalam kehidupan sehari-hari atau keadaan lain, dan membuktikan atau menciptakan atau menguji konjektur. Hudojo (dalam Setiawan: 2008) menyatakan bahwa pemecahan masalah merupakan suatu hal yang sangat esensial di dalam pengajaran matematika, sebab: (1) Siswa menjadi trampil menyeleksi informasi yang relevan, kemudian menganalisis dan akhirnya meneliti hasilnya. (2) Kepuasan intelekstual akan timbul dari dalam diri siswa. (3) Potensi intelekstual siswa meningkat.

Kemampuan pemecahan masalah digunakan untuk memecahkan masalah yang ada pada saat kegiatan pembelajaran. Pembelajaran berbasis masalah merupakan salah satu model pembelajaran yang menunjang dalam kegitan belajar mengajar kurikulum 2013. Menurut Arends (2008), mengemukakan bahwa terdapat lima fase sintaks secara umum dalam model pembelajaran berbasih masalah, yaitu orientasi permasalahan, pengorganisasian untuk meneliti, investigasi, mengembangkan dan presentasi serta menganalisis dan presentasi. Kemampuan pemecahan masalah siswa dalam kegiatan pembelajaran dapat dilihat dari motivasi belajar dan hasil belajar siswa.

Dari pemaparan tersebut dapat disimpulkan bahwa kemampuan pemecahan masalah merupakan kemampuan setiap individu siswa dalam menganalisa, mengenali, mencari solusi, mengkaji serta merencanakan solusi agar dapat melewati masalah yang dihadapi. Hasil belajar pada hakikatnya merupakan perubahan tingkah laku sebagai hasil belajar dalam pengertian luas yang mencakup ranah kognitif, afektif, dan psikomotor. Perubahan tingkah laku sebagai perubahan belajar sebagai hasil belajar. Menurut Slameto (2010) mengemukakan pendapatnya antara lain : 1) perubahan terjadi secara sadar; 2) perubahan dalam belajar bersifat kontinu dan fungsional; 3) Perubahan dalam belajar bersifat positif; 4) Perubahan dalam belajar bukan bersifat sementara; 5) Perubahan dalam belajar bertujuan atau terarah; 6) Perubahan dalam belajar mencakup seluruh aspek tingkah laku. Sedangkan menurut Mulyono (2003) mengatakan bahwa hasil belajar adalah perbuatan yang terarah pada penyelesain tugas-tugas belajar.

Dari uraian diatas dapat disimpulkan bahwa hasil belajar merupakan hasil yang dicapai oleh individu dalam kegiatan pembelajaran yang terarah dan bertujuan untuk mendapat perubahan tingkah laku dari individu terhadap keadaan yang lebih baik. Hasil belajar tiap individu ada yang tinggi, sedang, dan rendah sesuai dengan faktor-faktor yang mempengaruhinya.

Menurut Nasution (2003: 179), Kesiapan adalah kondisi yang mendahului kegiatan itu sendiri, tanpa kesiapan proses mental tidak terjadi. Dari uraian tersebut, maka kesiapan ialah keseluruhan kondisi seseorang yang membuatnya siap untuk mengatasi situasi permasalahan. Menurut Poerwodarminto (1991: 448) kerja diartikan sebagai kegaitan melakukan sesuatu untuk mencari nafkah atau mata pencaharian. Menurut Hasibuan (2003: 94) Kerja adalah pengorbanan jasa, jasmani dan pikiran untuk menghasilkan barang-barang atau jasa-jasa dengan memperoleh imbalan tertentu. Dari penjelasan yang telah dipaparkan tersebut dapat disimpulkan bahwa kesiapan kerja merupakan kesiapan seseorang dalam melaksanakan tugas yang 
diberikan, kemampuan melaksanakan pekerjaan, pengalaman dalam melakukan perkerjaan, serta komunikasi terhadap lingkungan kerja.

\section{METODE}

Penelitian ini merupakan penelitian yang bersifat ex post-facto karena data yang didapatkan adalah data hasil dari peristiwa yang sudah berlangsung, sehingga peneliti hanya mengungkapkan fakta berdasarkan pengukuran gejala yang telah ada pada responden (Arikunto, 2010: 17).

Penelitian ini bertujuan untuk mencari pengaruh variabel bebas motivasi belajar, kemampuan pemecahan masalah, dan hasil belajar terhadap variabel terikat yaitu kesiapan kerja. Penelitian ini merupakan penelitian kualitatif, karena penelitian ini bertujuan untuk mengetahui kemungkinan adanya hubungan sebab akibat dengan cara tertentu berdasarkan atas pengamatan terhadap akibat yang ada, kemudian mencari kembali faktor yang diduga menjadi penyebab, melalui pengumpulan data (Arikunto, 2010: 121).

Teknik pengumpulan data menggunakan metode dokumentasi dan angket. (1) Dokumentasi merupakan mencari data mengenai hal-hal atau variabel berupa buku-buku, dokumen, dan sebagainya (Arikunto, 2010:201). Dokumentasi ini digunakan untuk memperoleh data tentang hasil belajar siswa kelas XII Pemesinan SMK Pemuda 3 Kesamben, Blitar. (2) Menurut Sugiyono (2004:199) angket ialah teknik pengumpulan data yang dilakukan dengan cara memberi seperangkat pertanyaan atau penyataan tertulis kepada responden untuk dijawab. Angket digunakan untuk memperoleh data langsung dari responden dengan cara menjawab pertanyaan atau pernyataan secara tertulis mengenai pengaruh motivasi belajar, kemampuan pemecahan masalah dan kesiapan kerja.

Populasi adalah keseluruhan subyek penelitian (Arikunto, 2010: 30). Populasi dalam penelitian ini adalah siswa kelas XII Pemesinan SMK Pemuda 3 Kesamben, Blitar. Teknik pengambilan sampel yang digunakan dalam penelitian ini yaitu Nonprobability sampling berupa purposive sampling. Sampel dalam penelitian ini berjumlah 30 siswa.

Analisis data yang digunakan yaitu analisis deskriptif dan uji regresi. Adapun uji prasyrat sebelum hipotesis diujikan yaitu menggunakan uji validitas instrumen, uji reliabilitas, uji linearitas, dan uji multikolinieritas.

Arikunto (2002:144) mengemukakan bahwa validitas adalah suatu ukuran yang menunjukkan tingkat-tingkat kevalidan atau kesahihan suatu instrumen". Validitas instrumen diukur berdasarkan validitas isi (content validity) yaitu mengkaji kesesuaian pada item-item pertanyaan yang ada dengan indikator yang dikembangkan. Validitas instrumen diukur dengan menggunakan korelasi product moment Pearson. Adapun rumus product moment Pearson adalah sebagai berikut (Arikunto, 2002:146):

$$
r=\frac{n \sum X Y-\left(\sum X\right)\left(\sum Y\right)}{\sqrt{\left\{n \sum X^{2}-\left(\sum X\right)^{2}\right\}\left\{n \sum Y^{2}-\left(\sum Y\right)^{2}\right\}}}
$$

Dimana :

$\mathrm{r} \quad=$ Korelasi

$\mathrm{n} \quad$ = Banyaknya Sampel

$\mathrm{X}=$ Skor item $\mathrm{X}$

$\mathrm{Y} \quad=$ Skor Item $\mathrm{Y}$

Reliabilitas suatu pengujian ada kaitannya dengan pengujian validitas. "Reliabilitas adalah suatu nilai yang menunjukkan konsistensi suatu alat pengukur di dalam mengukur gejala yang sama" (Santoso, 2006:86). Jadi reliabilitas menunjukkan pada tingkat keterhandalan sesuatu. Untuk menguji reliabilitas digunakan rumus Alpha sebagai berikut (Arikunto, 2002:171): 


$$
r_{11}=\left[\frac{K}{(K-1)}\right]\left[1-\frac{\sum S_{b}^{2}}{S_{1}^{2}}\right]
$$

Dimana

$$
\begin{array}{ll}
r_{11} & =\text { Reliabilitas Instrumen } \\
\mathrm{K} & =\text { Banyaknya butir pertanyaan atau soal } \\
\sum_{b} S_{b}^{2} & =\text { Jumlah varian butir soal } \\
S_{1}^{2} & =\text { Varian butir soal }
\end{array}
$$

Uji linearitas bertujuan untuk mengetahui apakah variabel bebas memiliki hubungan yang linier terhadap variabel terikat. Uji multikolinieritas ini digunakan dan dipilih guna untuk menguji apakah pada model regresi ditemukan adanya korelasi antar variabel bebas. Model regresi yang baik seharusnya tidak terjadi korelasi antara variabel independen. Multikolinearitas diuji dengan menghitung nilai VIF (Variance Inflation Factor). Apabila nilai VIF kurang dari 10 dan Tolerance lebih dari 0,1 maka dinyatakan tidak terjadi multikolinearitas (Priyatno 2014: 165).

\section{HASIL}

\section{Pengaruh Motivasi Belajar Terhadap Kesiapan Kerja}

Berdasarkan analisis deskriptif diketahui bahwa nilai rata-rata motivasi belajar siswa adalah sebesar 76,80. Sedangkan nilai standar deviasi sebesar 8,795. Dari hasil klasifikasi motivasi belajar siswa didapatkan fakta bahwa siswa memiliki

\begin{tabular}{|c|c|c|}
\hline \multirow[t]{2}{*}{$N$} & Valid & 94 \\
\hline & Missing & 0 \\
\hline \multicolumn{2}{|c|}{ Mean } & 76.80 \\
\hline \multicolumn{2}{|c|}{ Median } & 77.00 \\
\hline \multicolumn{2}{|c|}{ Mode } & $74^{a}$ \\
\hline \multicolumn{2}{|c|}{ Std. Deviation } & 8.795 \\
\hline \multicolumn{2}{|c|}{ Variance } & 77.346 \\
\hline \multicolumn{2}{|c|}{ Range } & 63 \\
\hline \multicolumn{2}{|c|}{ Minimum } & 32 \\
\hline \multicolumn{2}{|c|}{ Maximum } & 95 \\
\hline
\end{tabular}
motivasi belajar yang tinggi. Dari 94 siswa, sebanyak 60 siswa $(63,8 \%)$ memiliki motivasi sangat tinggi, 29 siswa (30,9\%) memiliki motivasi tinggi, 3 siswa $(3,2 \%)$ memiliki motivasi sangat rendah, sedangkan 2 siswa $(2,1 \%)$ memiliki motivasi sangat rendah.

\section{Statistics}

a. Multiple modes exist. The smallest value is shown

Gambar 1. Statistik X1 


\begin{tabular}{|c|c|c|c|c|c|}
\hline \multicolumn{6}{|c|}{ kategoriX1 } \\
\hline & & Frequency & Percent & Valid Percent & $\begin{array}{c}\text { Cumulative } \\
\text { Percent }\end{array}$ \\
\hline \multirow[t]{5}{*}{ Valid } & sangat rendah & 2 & 2.1 & 2.1 & 2.1 \\
\hline & rendah & 3 & 3.2 & 3.2 & 5.3 \\
\hline & tinggi & 29 & 30.9 & 30.9 & 36.2 \\
\hline & sangat tinggi & 60 & 63.8 & 63.8 & 100.0 \\
\hline & Total & 94 & 100.0 & 100.0 & \\
\hline
\end{tabular}

Gambar 2. Kategori X1

Coefficients $^{\mathrm{a}}$

\begin{tabular}{|c|c|c|c|c|c|c|}
\hline \multirow{2}{*}{\multicolumn{2}{|c|}{ Model }} & \multicolumn{2}{|c|}{ Unstandardized Coefficients } & $\begin{array}{c}\text { Standardized } \\
\text { Coefficients }\end{array}$ & \multirow[b]{2}{*}{$t$} & \multirow[b]{2}{*}{ Sig. } \\
\hline & & $\mathrm{B}$ & Std. Error & Beta & & \\
\hline \multirow[t]{2}{*}{1} & (Constant) & 9.656 & 3.422 & & 2.822 & .006 \\
\hline & x1.total & .492 & .044 & .757 & 11.104 & .000 \\
\hline
\end{tabular}

a. Dependent Variable: y.total

Gambar 3. Hasil Uji Hipotesis Pertama

\section{Pengaruh Kemampuan Pemecahan Masalah terhadap Kesiapan kerja}

Berdasarkan analisis deskriptif diketahui bahwa nilai rata-rata kemampuan pemecahan masalah siswa adalah sebesar 53,51. Sedangkan nilai standar deviasi sebesar 6,589. Dari hasil klasifikasi kemampuan pemecahan masalah siswa didapatkan fakta bahwa siswa memiliki kemampuan pemecahan masalah yang sangat tinggi. Dari 94 siswa, sebanyak 61 siswa (64,9\%) memiliki kemampuan pemecahan masalah sangat tinggi, 31 siswa (33\%) memiliki kemampuan pemecahan masalah tinggi, sedangakan 2 siswa $(2,1 \%)$ memiliki kemampuan pemecahan masalah sangat rendah.

\section{Statistics}

\begin{tabular}{|c|c|c|}
\hline \multicolumn{3}{|c|}{ x2.total } \\
\hline$N$ & Valid & 94 \\
\hline & Missing & 0 \\
\hline Me & & 53.51 \\
\hline Me & & 54.50 \\
\hline Mo & & 56 \\
\hline Std & iation & 6.589 \\
\hline Var & & 43.414 \\
\hline Ra & & 44 \\
\hline Min & & 22 \\
\hline Ma: & & 66 \\
\hline
\end{tabular}

Gambar 4. Statistik X2 
kategori_X2

\begin{tabular}{|c|c|c|c|c|c|}
\hline & & Frequency & Percent & Valid Percent & $\begin{array}{c}\text { Cumulative } \\
\text { Percent }\end{array}$ \\
\hline \multirow[t]{4}{*}{ Valid } & sangat rendah & 2 & 2.1 & 2.1 & 2.1 \\
\hline & tinggi & 31 & 33.0 & 33.0 & 35.1 \\
\hline & sangat tinggi & 61 & 64.9 & 64.9 & 100.0 \\
\hline & Total & 94 & 100.0 & 100.0 & \\
\hline
\end{tabular}

Gambar 5. Kategori X2

Coefficients $^{\mathrm{a}}$

\begin{tabular}{|c|c|c|c|c|c|c|}
\hline \multirow{2}{*}{\multicolumn{2}{|c|}{ Model }} & \multicolumn{2}{|c|}{ Unstandardized Coefficients } & \multirow{2}{*}{$\begin{array}{c}\begin{array}{c}\text { Standardized } \\
\text { Coefficients }\end{array} \\
\text { Beta }\end{array}$} & \multirow[b]{2}{*}{$t$} & \multirow[b]{2}{*}{ Sig. } \\
\hline & & $\mathrm{B}$ & Std. Error & & & \\
\hline \multirow[t]{2}{*}{1} & (Constant) & 8.285 & 2.619 & & 3.163 & .002 \\
\hline & x2.total & .731 & .049 & .843 & 15.046 & .000 \\
\hline
\end{tabular}

a. Dependent Variable: $y$.total

Gambar 6. Hasil Uji Hipotesis Kedua

\section{Pengaruh Hasil Belajar Terhadap Kesiapan kerja}

Berdasarkan analisis deskriptif diketahui bahwa nilai rata-rata hasil belajar siswa adalah sebesar 53,51. Sedangkan nilai standar deviasi sebesar 6,589. Dari hasil klasifikasi hasil belajar siswa didapatkan fakta bahwa siswa memiliki hasil belajar yang tinggi. Dari 94 siswa, sebanyak 61 siswa (64,9\%) memiliki hasil belajar sangat tinggi, 31 siswa (33\%) memiliki hasil belajar tinggi, sedangakan 2 siswa $(2,1 \%)$ memiliki hasil belajar sangat rendah.

\section{Statistics}

\begin{tabular}{|l|r|}
\hline $\mathrm{N} 3 \quad$ Valid & 94 \\
& Missing \\
Mean & 0 \\
Median & 81.74 \\
Mode & 81.00 \\
Std. Deviation & 79 \\
Variance & 3.276 \\
Range & 10.730 \\
Minimum & 14 \\
Maximum & 76 \\
\hline
\end{tabular}

Gambar 7. Statistik X3 
kategori_X3

\begin{tabular}{|ll|r|r|r|r|}
\hline & & Frequency & Percent & Valid Percent & $\begin{array}{c}\text { Cumulative } \\
\text { Percent }\end{array}$ \\
\hline Valid & tinggi & 81 & 86.2 & 86.2 & 86.2 \\
& sangat tinggi & 13 & 13.8 & 13.8 & 100.0 \\
& Total & 94 & 100.0 & 100.0 & \\
\hline
\end{tabular}

Gambar 8. Kategori X3

Coefficients $^{a}$

\begin{tabular}{|c|c|c|c|c|c|c|}
\hline \multirow{2}{*}{\multicolumn{2}{|c|}{ Model }} & \multicolumn{2}{|c|}{ Unstandardized Coefficients } & \multirow{2}{*}{$\begin{array}{c}\begin{array}{c}\text { Standardized } \\
\text { Coefficients }\end{array} \\
\text { Beta }\end{array}$} & \multirow[b]{2}{*}{$t$} & \multirow[b]{2}{*}{ Sig. } \\
\hline & & $\mathrm{B}$ & Std. Error & & & \\
\hline \multirow[t]{2}{*}{1} & (Constant) & 51.115 & 14.869 & & 3.438 & .001 \\
\hline & $x 3$ & -.045 & .182 & -.026 & -.250 & .803 \\
\hline
\end{tabular}

a. Dependent Variable: y.total

\section{Gambar 9. Hasil Hipotesis Ketiga}

\section{Pengaruh Motivasi Belajar, Kemampuan Pemecahan Masalah, Dan Hasil Belajar Terhadap Kesiapan Kerja}

Berdasarkan analisis deskriptif diketahui bahwa nilai rata-rata kesiapan kerja siswa adalah sebesar 47,40. Sedangkan nilai standar deviasi sebesar 5,712. Dari hasil klasifikasi kesiapan kerja siswa didapatkan fakta bahwa siswa memiliki kesiapan kerja yang sangat tinggi. Dari 94 siswa, sebanyak 59 siswa (62,8\%) memiliki kesiapan sangat tinggi, 33 siswa (35,1\%) memiliki kesiapan kerja tinggi, 1 siswa $(1,1 \%)$ memiliki kesiapan kerja rendah, sedangakan 1 siswa $(1,1 \%)$ memiliki kesiapan kerja sangat rendah.

\section{Statistics}

\begin{tabular}{|c|c|c|}
\hline \multirow[t]{2}{*}{ N } & Valid & 94 \\
\hline & Missing & 0 \\
\hline \multicolumn{2}{|c|}{ Mean } & 47.40 \\
\hline \multicolumn{2}{|c|}{ Median } & 48.00 \\
\hline \multicolumn{2}{|c|}{ Mode } & $45^{\mathrm{a}}$ \\
\hline \multicolumn{2}{|c|}{ Std. Deviation } & 5.712 \\
\hline \multicolumn{2}{|c|}{ Variance } & 32.631 \\
\hline \multicolumn{2}{|c|}{ Range } & 36 \\
\hline \multicolumn{2}{|c|}{ Minimum } & 22 \\
\hline \multicolumn{2}{|c|}{ Maximum } & 58 \\
\hline
\end{tabular}

a. Multiple modes exist. The smallest value is shown

Gambar 10. Statistik X1, X2, X3, Terhadap Y 


\begin{tabular}{|ll|r|r|r|r|}
\hline \multicolumn{1}{|c|}{ kategori_Y } \\
\hline & Frequency & Percent & Valid Percent & $\begin{array}{c}\text { Cumulative } \\
\text { Percent }\end{array}$ \\
\hline Valid & sangat rendah & 1 & 1.1 & 1.1 & 1.1 \\
& rendah & 1 & 1.1 & 1.1 & 2.1 \\
& tinggi & 33 & 35.1 & 35.1 & 37.2 \\
& sangat tinggi & 59 & 62.8 & 62.8 & 100.0 \\
Total & 94 & 100.0 & 100.0 & \\
\hline
\end{tabular}

Gambar 11. Kategori X1, X2, X3, Terhadap Y

\begin{tabular}{|c|c|c|c|c|c|c|}
\hline \multicolumn{7}{|c|}{ Coefficients $^{a}$} \\
\hline \multirow{2}{*}{\multicolumn{2}{|c|}{ Model }} & \multicolumn{2}{|c|}{ Unstandardized Coefficients } & \multirow{2}{*}{$\begin{array}{c}\begin{array}{c}\text { Standardized } \\
\text { Coefficients }\end{array} \\
\text { Beta }\end{array}$} & \multirow[b]{2}{*}{$t$} & \multirow[b]{2}{*}{ Sig. } \\
\hline & & $\mathrm{B}$ & Std. Error & & & \\
\hline \multirow[t]{4}{*}{1} & (Constant) & 9.179 & 8.254 & & 1.112 & .269 \\
\hline & $\mathrm{x} 1$.total & .151 & .059 & .233 & 2.557 & .012 \\
\hline & x2.total & .570 & .079 & .657 & 7.227 & .000 \\
\hline & x3 & -.047 & .095 & -.027 & -.496 & .621 \\
\hline
\end{tabular}

\section{Hasil Uji Linearitas}

Uji Linearitas Hubungan Variabel Motivasi Belajar Terhadap Kesiapan Kerja

Hasil uji linearitas terhadap hubungan variabel motivasi belajar terhadap variabel kesiapan kerja didapatkan nilai $\mathrm{F}_{\text {hitung }}$ sebesar 132,242 dengan signifikansi 0,000. Oleh karena signifikansi sebesar 0,0001 lebih kecil dari 0,050 maka dapat disimpulkan bahwa hubungan variabel motivasi belajar terhadap variabel kesiapan kerja adalah linier.

\begin{tabular}{cccc}
\hline $\begin{array}{c}\text { Hubungan Antar } \\
\text { Variabel }\end{array}$ & Nilai f finan & Asymp. Sig. & Kesimpulan \\
\hline $\begin{array}{c}\text { hasil belajar vs } \\
\text { kesiapan kerja }\end{array}$ & 0,065 & 0,000 & $\begin{array}{c}\text { Hubungan } \\
\text { kedua variabel } \\
\text { linier }\end{array}$ \\
\hline
\end{tabular}

Gambar 13. Hasil Uji Linearitas X1 Terhadap Y

\section{Uji Linearitas Hubungan Variabel Kemampuan Pemecahan Masalah Terhadap Kesiapan Kerja}

Hasil uji linieritas terhadap hubungan variabel motivasi belajar terhadap variabel kesiapan kerja didapatkan nilai $\mathrm{F}_{\text {hitung }}$ sebesar 132,242 dengan signifikansi 0,000. Oleh karena signifikansi sebesar 0,0001 lebih kecil dari 0,050 maka dapat disimpulkan bahwa hubungan variabel motivasi belajar terhadap variabel kesiapan kerja adalah linier

\begin{tabular}{cccc}
\hline $\begin{array}{c}\text { Hubungan Antar } \\
\text { Variabel }\end{array}$ & Nilai f $_{\text {hitung }}$ & Asymp. Sig. & Kesimpulan \\
\hline $\begin{array}{c}\text { Kemampuan } \\
\text { pemecahan masalah } \\
\text { vs kesiapan keria }\end{array}$ & 249,571 & 0,000 & $\begin{array}{c}\text { Hubungan } \\
\text { kedua variabel } \\
\text { linier }\end{array}$ \\
\hline \multicolumn{2}{c}{ Gambar 14. Hasil Uji Linearitas X2 Terhadap Y } &
\end{tabular}

Uji Linearitas Hubungan Variabel Hasil Belajar Terhadap Kesiapan Kerja 
Hasil uji linieritas terhadap hubungan variabel hasil belajar terhadap variabel kesiapan kerja didapatkan nilai $\mathrm{F}_{\text {hitung }}$ sebesar 0,65dengan signifikansi 0,000. Oleh karena signifikansi sebesar 0,0001 lebih kecil dari 0,050 maka dapat disimpulkan bahwa hubungan variabel hasil belajar terhadap variabel kesiapan kerja adalah linier.

\begin{tabular}{cccc}
\hline $\begin{array}{c}\text { Hubungan Antar } \\
\text { Variabel }\end{array}$ & Nilai $\mathrm{f}_{\text {hitung }}$ & Asymp. Sig. & Kesimpulan \\
\hline $\begin{array}{l}\text { hasil belajar vs } \\
\text { kesiapan kerja }\end{array}$ & 0,065 & 0,000 & $\begin{array}{c}\text { Hubungan } \\
\text { kedua variabel } \\
\text { linier }\end{array}$ \\
\hline
\end{tabular}

Gambar 15. Hasil uji linearitas X3 terhadap Y

\section{Uji Multikolinearitas}

Uji multikolinearitas dilakukan untuk menyimpulkan apakah antara variabel bebas dalam persamaan regresi tidak saling berkorelasi. Multikolinearitas dapat dideteksi dengan melihat nilai korelasi, apabila nialai korelasi antar variabel bebas kurang dari 0,6 maka tidak terjadi multikolinearitas, sebaliknya jika nilai korelasi lebih dari 0,6 maka terjadi multikolinearitas.

\begin{tabular}{|c|c|c|c|c|}
\hline \multirow{2}{*}{ Variabel Bebas } & \multicolumn{3}{|c|}{ Coefficient Correlation } & \multirow{2}{*}{ Keterangan } \\
\hline & $\mathbf{X l}$ & $\mathbf{X} 2$ & $\mathbf{X} 3$ & \\
\hline $\mathrm{X} 1$ & 1 & $-0,799$ & $-0,055$ & \\
\hline $\mathrm{X} 2$ & $-0,799$ & 1 & 0,49 & $\begin{array}{c}\text { Semua Variabel } \\
\text { Bebas Tidak } \\
\text { Terdapat }\end{array}$ \\
\hline $\mathrm{X} 3$ & $-0,055$ & 0,49 & 1 & Multikolinearitas \\
\hline
\end{tabular}

Gambar 16. Hasil Uji Multikolinearitas

\section{PEMBAHASAN}

\section{Pengaruh Motivasi Belajar Terhadap Kesiapan Kerja}

Dari hasil analisis data diketahui variabel motivasi belajar berpengaruh langsung terhadap kesiapan kerja siswa kelas XII pemesinan SMK Pemuda 3 Kesamben, Blitar. Hal ini ditunjukkan dari nilai standarisasi koefisiem beta sebesar 0,757 yang artinya ada pengaruh yang positif (searah) antara motivasi belajar terhadap kesiapan kerja sisw kelas XII Pemesinan SMK Pemuda 3 Kesamben, Blitar. Hal ini berarti dengan adanya motivasi belajar semakin menambah tingkat kesiapan kerja siswa.

\section{Pengaruh Kemampuan Pemecahan Masalah Terhadap Kesiapan Kerja}

Dari hasil analisis data diketahui variabel kemampuan pemecahan masalah berpengaruh langsung terhadap kesiapan kerja siswa kelas XII pemesinan SMK Pemuda 3 Kesamben, Blitar. Hal ini ditunjukkan dari nilai standarisasi koefisiem beta sebesar 0,843 yang artinya ada pengaruh yang positif (searah) antara kemampuan pemecahan masalah terhadap kesiapan kerja sisw kelas XII Pemesinan SMK Pemuda 3 Kesamben, Blitar. Hal ini berarti dengan adanya kemampuan pemecahan masalah semakin menambah tingkat kesiapan kerja siswa.

\section{Pengaruh Hasil Belajar Terhadap Kesiapan Kerja}

Dari hasil analisis data diketahui variabel hasil belajar berpengaruh tidak langsung terhadap kesiapan kerja siswa kelas XII pemesinan SMK Pemuda 3 Kesamben, Blitar. Hal ini ditunjukkan dari nilai standarisasi koefisiem beta sebesar -0,026. Hasil belajar merupakan nilai plus untuk siswa yang telah menyelesaikan tugas. Hal ini hasil belajar berpengaruh tidak langsung terhadap kesiapan kerja siswa.

\section{Pengaruh Motivasi Belajar, Kemampuan Pemecahan Masalah, Dan Hasil Belajar Terhadap Kesiapan Kerja}


Dari hasil analisis data pada pengujian hipotesis berganda, didapat hasil standarisasi beta sebesar 0,233 untuk variabel motivasi belajar, 0,657 untuk varibel kemampuan penyelesaian masalah, sedangkan untuk hasil belajar sebesar -0,027. Dapat simpulkan bahwa terdapat pengaruh secara langsung dan tidak langsung terhadap kesiapan kerja siswa kelas XII Pemesinan SMK Pemuda 3 Kesamben, Blitar.

\section{PENUTUP}

Berdasarkan pembahasan penelitian, dapat ditarik simpulan sebagai berikut. Hasil analisis data diketahui variabel motivasi belajar berpengaruh langsung terhadap kesiapan kerja siswa kelas XII pemesinan SMK Pemuda 3 Kesamben, Blitar. Hal ini ditunjukkan dari nilai standarisasi koefisiem beta sebesar 0,757 yang artinya ada pengaruh yang positif (searah) antara motivasi belajar terhadap kesiapan kerja sisw kelas XII Pemesinan SMK Pemuda 3 Kesamben, Blitar. Hal ini berarti dengan adanya motivasi belajar semakin menambah tingkat kesiapan kerja siswa.

Dari hasil analisis data diketahui variabel kemampuan pemecahan masalah berpengaruh langsung terhadap kesiapan kerja siswa kelas XII pemesinan SMK Pemuda 3 Kesamben, Blitar. Hal ini ditunjukkan dari nilai standarisasi koefisiem beta sebesar 0,843 yang artinya ada pengaruh yang positif (searah) antara kemampuan pemecahan masalah terhadap kesiapan kerja sisw kelas XII Pemesinan SMK Pemuda 3 Kesamben, Blitar. Hal ini berarti dengan adanya kemampuan pemecahan masalah semakin menambah tingkat kesiapan kerja siswa.

Dari hasil analisis data diketahui variabel hasil belajar berpengaruh tidak langsung terhadap kesiapan kerja siswa kelas XII pemesinan SMK Pemuda 3 Kesamben, Blitar. Hal ini ditunjukkan dari nilai standarisasi koefisiem beta sebesar -0,026. Hasil belajar merupakan nilai plus untuk siswa yang telah menyelesaikan tugas. Hal ini hasil belajar berpengaruh tidak langsung terhadap kesiapan kerja siswa.

Dari hasil analisis data pada pengujian hipotesis berganda, didapat hasil standarisasi beta sebesar 0,233 untuk variabel motivasi belajar, 0,657 untuk varibel kemampuan penyelesaian masalah, sedangkan untuk hasil belajar sebesar -0,027. Dapat simpulkan bahwa terdapat pengearuh secara langsung dan tidak langsung terhadap kesiapan kerja siswa kelas XII Pemesinan SMK Pemuda 3 Kesamben, Blitar.

\section{DAFTAR RUJUKAN}

Arends, Richard I. 2008. Learning To Teach Belajar Untuk Mengajar. (Edisi Ketujuh/ Buku Dua). Terjemahan Helly Pajitno Soetjipto \& Sri Mulyantini Soetjipto. Yogyakarta: Pustaka Pelajar.

Arikunto, S. 2010. Prosedur Penelitian Suatu Pendekatan Praktik. Bandung: PT. Remaja Rosda karya Arikunto, S. 2010. Prosedur Penelitian Suatu Pendekatan Praktik. Bandung: PT. Remaja Rosda karya. Arikunto, Suharsimi. 2002. Prosedur Pendekatan Suatu Pendekatan Praktek. Jakarta: Rineka Cipta. Djamarah, S. 2002. Psikologi Belajar. Jakarta: Rineka Cipta.

Haling, Abdul, Dkk. 2007. Perencanaan Pembelajaran. Cet.1. Makassar: Badan Penerbit UNM.

Hasibuan, Malayu S.P.. 2003. Manajemen Sumber Daya Manusia. Jakarta: Bumi Aksara.

Khodijah, N. 2014. Psikologi Pendidikan.Jakarta: Rajawali Press.

Mulyono, Abdurrahman. 2003. Pendidikan Bagi Anak Berkesulitan Belajar, Jakarta: Rineka Cipta.

Nasution, S. 2003. Berbagai Pendekatan Dalam Proses Belajar Mengajar. Jakarta: Bumi Aksara.

Poerwodarminto. 2002. Kamus Besar Bahasa Indonesia. Jakarta : Balai Pustaka

Priyatno, Dwi. 2014. SPSS 22: Pengolah Data Terpraktis. Yogyakarta: CV ANDI.

Setiawan, Andri. 2008. Pembelajaran Berbasis Masalah Untuk Meningkatkan Kemampuan Komunikasi Dan Pemecahan Masalah Matmatika Siswa Sekolah Menengah Pertama. Tesis: UPI Bandung.

Slameto. 2010. Belajar Dan Faktor-Faktor Yang Mempengaruhinya. Jakarta: Rineka Cipta.

Sugiyono. 2004. Metode Penelitian Bisnis. Bandung: Alfabeta

Sumarmo, Utari. 2008. Pembelajaran Matematika. Dalam Rohman Natawidjaja, Dkk, (Ed), Rujukan Filsafat Teori Dan Praktis Ilmu Pendidikan.Bandung: UPI Press.

Universitas Negeri Malang. 2017. Pedoman Penulisan Karya Ilmiah: Skripsi, Tesis, Disertasi, Artikel, Makalah, Tugas Akhir, Laporan Penelitian. Edisi 2017. Malang: Universitas Negeri Malang.

Uno, B.H. 2007. Teori Motivasi Dan Pengukurannya. Jakarta: Bumi Aksara.

Uno, H. 2008. Teori Motivasi Dan Pengukurannya. Jakarta: PT. Bumi Aksara 